có giá trị trung bình chỉ số CAVI và tỷ lệ tăng cao hơn so với nhóm bệnh nhân không có đặc điểm này, $p<0,05$. Đái tháo đường là một yếu tố nguy cơ bệnh tim mạch, trong đó có vữa xơ mạch máu và các biến cố tim mạch. Tăng huyết áp và ĐTĐ cùng tồn tại ở 30-80\% bệnh nhân và làm tăng nguy cơ mắc bệnh tim mạch. Tăng huyết áp làm tăng nguy cở CAVI bất thường ở người bệnh ĐTÐ với nguy cơ tương đối gấp 2,43 lần so với người khỏe mạnh. Trong bệnh ĐTÐ, cơ chế chính của việc tăng độ cứng động mạch là tăng cường tạo ra và tích tụ các sản phẩm cuối glycation tiên tiến (AGEs) trong thành mạch, gây ra liên kết chéo quá mức giữa AGEs và các phân tử collagen của chất nền ngoại và dẫn đến dày lớp nội trung mạc và làm cứng thành động mạch. Trong tăng huyết áp, xơ cứng động mạch xảy ra do tăng áp lực nội mạc gây ra cắng thẳng dễ rung động tăng dẫn đến suy thoái elastin và kích thích sản xuất collagen. Những đặc điểm này làm chỉ số CAVI cao hơn.

\section{KẾT LUÂN}

- Chỉ số CAVI trung bình ở bệnh nhân thân nhân tạo chu kỳ là $9,96 \pm 2,14$, cao hơn những người bình thường là $8,14 \pm 0,59$, có ý nghĩa $p<$ 0,001. Có tới $66,7 \%$ bệnh nhân tăng chỉ số CAVI so nhóm chứng.

- Nhóm bệnh nhân tuổi $\geq 60$; thời gian TNT $\geq 5$ năm; mất chức năng thận tồn dư; đái tháo đường; THA có giá trị trung bình và hoặc tỷ lệ tăng chỉ số CAVI cao hơn nhóm bênh nhân không có đặc điểm trên, $p<0,05$. Chỉ số CAVI có mối tương quan thuận, mức độ không chặt với thời gian TNT, $r=0,247, p<0,01$.

\section{TÀI LIÊU THAM KHẢO}

1. Chen J, Budoff MJ, Reilly MP, et al. (2017). Coronary Artery Calcification and Risk of Cardiovascular Disease and Death Among Patients With Chronic Kidney Disease. JAMA Cardiol. 2(6):635-643.

2. Thomas R., Kanso A., Sedor J.R. (2008). Chronic kidney disease and its complications. Prim Care, 35(2): $329-32$.

3. Ichihara A, Yamashita $N$, Takemitsu $T$, et al. (2008). Cardio-ankle vascular index and ankle pulse wave velocity as a marker of arterial fibrosis in kidney failure treated by hemodialysis. Am J Kidney Dis, 52(5), 947-955.

4. Kato A, Takita T, Furuhashi $M$, et al. (2012). Brachial-Ankle Pulse Wave Velocity and the CardioAnkleVascular Index as a Predictor of Cardiovascular Outcomesin Patients on Regular Hemodialysis. Therapeutic Apheresis and Dialysis 16 (3): 232-241.

5. Takenaka T, Hoshi $H$, Kato $N$, et al (2008). Cardio-Ankle Vascular Index to Screen Cardiovascular Diseases in Patients with End-Stage Renal Diseases. J Atheroscler Thromb 15: 339-44.

6. Jeznach-Steinhagen A, Słotwiński R, Szczygieł B. (2007). Malnutrition, inflammation, atherosclerosis in hemodialysis patients. RocZ Panstw Zakl Hig. 58(1):83-8.

7. Nagayama D., Saiki A., Endo K., Yamaguchi T., et al. (2010). Improvement of cardio-ankle vascular index by glimepiride in type 2 diabetic patients. Int J Clin Pract, 64(13), pp. 1796-1801.

8. Takafumi Okura, Sanae Wanatabe, et al. (2007). Relationship betwen cardio ankle vascular index (CAVI) and carotid atherosclerosis in patients with essential hypertension. Hypertens Res 30 (4): 335-340.

\title{
KHẢO SÁT HÌNH THÁI VÀ LIÊN QUAN VỚI CẤU TRÚC CÂN BÊN CỦA XOANG BƯỚM TRÊN PHIM CHỤP CẮT LỚP VI TÍNH ĐA DÃY
}

\section{TÓM TẮT}

Mục tiêu; Khảo sát hình thái và liên quan với các cấu trúc cận bên của xoang bướm trên phim chụp cắt lớp vi tính đa dãy (CLVT). Đối tướng và phương pháp: Gồm 60 bệnh nhân (BN) (tuổi từ 18 đến 92), nam chiếm $35 / 60 \quad(58,3 \%)$ và nữ chiếm $25 / 60$ $(41,7 \%)$ được chụp CLVT đa dãy sọ não tại Bệnh viện Việt Đức Hà Nội, được xử lý bằng phầm mềm Radiant

\footnotetext{
${ }^{1}$ Trường Đai hoc Y Dướ Thái Bình

Chịu trách nhiệm chính: Vũ Duy Tùng

Email: tunganatomy@gmail.com

Ngày nhận bài: 18/4/2021

Ngày phản biên khoa họ: 15/5/2021

Ngày duyệt bài: 12/6/2021
}

Vũ Duy Tùng ${ }^{1}$, Trần Thị Hằng ${ }^{1}$

khảo sát dưới 3 măt phẳng (MP) tái taoo. Chúng tôi khảo sát các loại khí hóa xoang bướm mở rộng: dốc nền, ngách bên, cánh nhỏ, Iõm trước và sự lồi, mất thành xương (phơi trân) của các cấu trúc động mạch cảnh trong (ĐMCT), thần kinh thị giác (TKTंG), thần kinh hàm trên (TKV2) và thần kinh Vidian (TKVidian) vào xoang bướm. Kết quả: $100 \%$ bệnh nhân quan sát đước xoang bướm rõ nét trên phim. Tỷ lệ loai khí hóa mở rộng ngách bên và dốc nền đều là $63,3 \%$, loại cánh nhỏ là $30 \%$ và loai Iõm trước là $20 \%$. Đông mạch cảnh trong lồi vào xoang bướm $71,7 \%$, phới trần $10 \%$. Thần kinh thi giác lồi vào xoang bướm $49,2 \%$, phơi trân $7,5 \%$, Thần kinh hàm trên lồi vào xoang bướm $37,5 \%$, phơi trần 3,3\%. Thần kinh vidian lồi vào xoang bướm 44,2\%, phơi trân 19,2\%. Theo thống kê có sự liên quan giữa khí hóa mở rộng sang 
bên với lồi ĐMCT $(p<0,05)$, TKV2 $(p<0,0001)$ và TKVidian $(p<0,0001)$; giữa khí hóa mở rộng cánh nhỏ với lồi thần kinh thị giác $(p<0,0001)$. Kết luận: Sự biến đổi hình thái và liên quan của xoang bướm với các cấu trúc cận bên của xoang bướm cố xu hướng làm tăng biến chứng phức tạp trong phẫu thuật nội soi vào xoang bướm và các phẫu thuật tuyến yên và vùng quanh yên bằng đường mổ nội soi qua xoang bướm. Điều này đời hỏi một sự hiểu biết toàn diện về hình thái giải phẫu và liên quan với cấu trúc cận bên xoang bướm.

Tư khóa: Hình thái xoang bướm, liên quan cận bên xoang bướm, phấu thuật nội soi qua xoang bướm.

\section{SUMMARY \\ ANATOMIC VARIATIONS OF SPHENOID SINUS AND RELATED ADJACENT STRUCTURES - A STUDYBY IMAGING MULTIDETECTOR COMPUTED TOMOGRAPHY}

Purpose: Study on anatomic variations of sphenoid sinus and related adjacent structures by 3D imaging helical CT scan. Materials and methods: This retrospective study included 60 patients who underwent CT of the paranasal sinuses. The multiplanar reformations of paranasal sinus were assessed for the type of pneumatization of the sphenoid sinus and type of clival, lateral recess, lesser wing, and anterior recess extensions and protrusion and dehiscence of internal carotid artery (ICA), optic never (ON), maxillary never (MN) and vidian never (VN). Results: The extensions of pneumatization subtypes in the study were clival in $63,3 \%$ subjects; lateral recess, lesser wing, and anterior recess in $63,3 \%, 30 \%$ and $20 \%$. Protrusion and dehiscence of ICA, ON, MN, and VN were noticed in $71,7 \%$ and $10 \% ; 49,2 \%$ and $7,5 \% ; 37,5 \%$ and $3,3 \%$ and $44,2 \%$ and $19,2 \%$. There was a statistically significant correlation between the lateral recess pneumatization and carotid canal protrusion $(p<0,001)$; vidian canal protrusion $(p<0.001)$, and foramen rotundum protrusion $(p<0.001)$. The optic canal protrusion was found to be significantly associated with theanterior clinoid and lesser wing pneumatization $(p<0.001)$. Conclusion: The anatomical variations of the sphenoid sinus tend to give rise to a complexity of symptoms and potentially serious complications. This variability necessitates a comprehensive understanding of the regional sphenoid sinus anatomy by a detailed imaging multidetector computed computed tomography sinus examination.

Key words: Anatomic variations of phenoid sinus; Relate Adjacent structures Transsphenoidal endoscopic surgery.

\section{I. ĐĂT VẤN ĐỀ}

Xoang bướm (XB) là một xoang xoang nằm sau và khó tiếp cận nhất trong các xoang cạnh mũi, xoang nằm trong xương bướm là phần trung tâm của nền sọ. Xoang được bao quanh bởi các cấu trúc thần kinh và mạch máu quan trọng như động mạch cảnh trong, thần kinh thị giác, thần kinh V2, thần kinh Vidian. Xoang bướm thường có nhiều biến đổi về hình thái do quá trình khí hóa xoang từ rất hẹp đến rất rộng. Xoang có thể khí hóa mở rộng vào cánh lớn xương bướm, chân bướm, dốc nền, cánh nhỏ xương bướm đôi khi vào mỏm yên trước (mấu giường trước). Theo mức độ khí hóa, các cấu trúc thần kinh và mach máu cận bên có thể nhô vào lòng hoặc chạy trong xoang bướm, thành xương ngăn cách các cấu trúc này thay đổi có thể rất móng thậm chí không còn.[1] Điều này có thể là nguyên nhân của các tổn thương trong khi tiếp cận mở rộng của các phẫu thuật nội soi mũi qua xoang bướm đến tổn thương vùng não giữa, xương đá, tuyến yên [2]. Vì vậy nắm được kiến thức về những biến thể này và ý nghĩa của chúng cho phép chúng tôi nêu bật lên được tầm quan trọng với bác sĩ phẫu thuật, hỗ trợ lựa chọn, hướng dẫn phẫu thuật, dự phòng các biến chứng trong và sau mổ.Trong thăm dò khảo sát xoang bướm xác định mốc giải phẫu phục vụ cho chẩn đoán và điều trị đặc biệt trong khảo sát trước mổ thì chụp cắt lớp vi tính đa dãy có nhiều ưu thế vì đây là phương pháp khảo sát đơn giản, không gây khó chịu cho người bệnh, cùng vời phần mềm đọc cho phép tái tạo hình ảnh trong không gian 3 chiều thì xoang bướm cùng với cấu trúc cận bên được khảo sát một cách tổng quát và cụ thể. Nghiên cứu khảo sát hình thái và liên quan cận bên xoang bướm trên phim chụp cắt lớp vi tính đa dãy nhằm xác định tỷ lệ các dạng xoang bướm và liên quan với cấu trúc cận bên.

\section{II. ĐỐI TƯợNG VÀ PHƯƠNG PHÁP NGHIÊN CỨU}

1. Đối tượng nghiên cứu: 60 tâp hình ảnh CLVT đa dãy vùng đầu từ tháng $07 / 2018$ - tháng 07/2019 tại Bệnh viện Việt Đức Hà Nội. Loại trừ phim không rõ̃ nét, bất thường bẩm sinh khối sọ mặt, có bệnh lý mũi xoang, phẫu thuật mũi xoang, bệnh lý gây biến dạng các mốc giải phẫu vùng sọ - xoang, gây tạo - hủy xương và bệnh nhân dưới 16 tuổi.

2. Phương pháp nghiên cứu: Nghiên cứu hồi cứu mô tả cắt ngang.

\section{Phương tiện nghiên cứu}

Hình ảnh CLVT sọ não với độ mỏng giữa các lát cắt là $0,6 \mathrm{~mm}$ thu được từ máy chụp CLVT đa dãy thỏa mãn tiêu chuẩn.

Data hình ảnh được lưu lại vào đĩa DVD và sau đó trên máy tính hình ảnh CT được phân tích trên phần mềm Radiant 4.6.9.

Phần mềm nhập và xử lý số liệu SPSS 20.0 
III. KẾT QUẢ NGHIÊN CỨU

1. Hình thái xoang bướm theo sự khí hóa mở rộng

Bảng 3.1. Tỷ lệ các dạng khí hóa mở rộng xoang bướm ( $n=60)$

\begin{tabular}{|c|c|c|c|c|}
\hline $\begin{array}{ll}\text { Dạng khí hóa MR } & \text { Xoang bướm MR } \\
\end{array}$ & $\begin{array}{l}\text { Không } \\
\text { n (\%) }\end{array}$ & $\begin{array}{c}\text { Phải } \\
\text { n (\%) }\end{array}$ & $\begin{array}{c}\text { Trái } \\
\text { n (\%) }\end{array}$ & $\begin{array}{l}\text { Hai bên } \\
\text { n (\%) }\end{array}$ \\
\hline \multirow{2}{*}{ Ngách bên } & \multirow{2}{*}{$22(36,7)$} & $5(8,3)$ & $10(16,7)$ & $23(38,3)$ \\
\hline & & \multicolumn{3}{|c|}{$38(63,3)$} \\
\hline \multirow{2}{*}{ Dốc nền } & \multirow{2}{*}{$22(36,7)$} & $11(18,3)$ & $10(16,7)$ & $17(28,3)$ \\
\hline & & \multicolumn{3}{|c|}{$38(63,3)$} \\
\hline \multirow{2}{*}{ Cánh nhỏ } & \multirow{2}{*}{$42(70,0)$} & $3(5,0)$ & $7(11,7)$ & $8(13,3)$ \\
\hline & & \multicolumn{3}{|c|}{$18(30,0)$} \\
\hline \multirow{2}{*}{ Lõm trước } & \multirow{2}{*}{$48(80,0)$} & $6(10,0)$ & $4(6,7)$ & $2(3,3)$ \\
\hline & & \multicolumn{3}{|c|}{$12(20,0)$} \\
\hline
\end{tabular}

Nhận xét: Trong 60 bệnh nhân nghiên cứu thì loại mở rộng ngách bên, dốc nền chiếm chủ yếu với $63 \%$, thấp hơn chiếm $30 \%$ là dạng mở rộng vào cánh nhỏ, mấu giường trước và thấp nhất là khí hóa dạng lõm trước với $20 \%$.
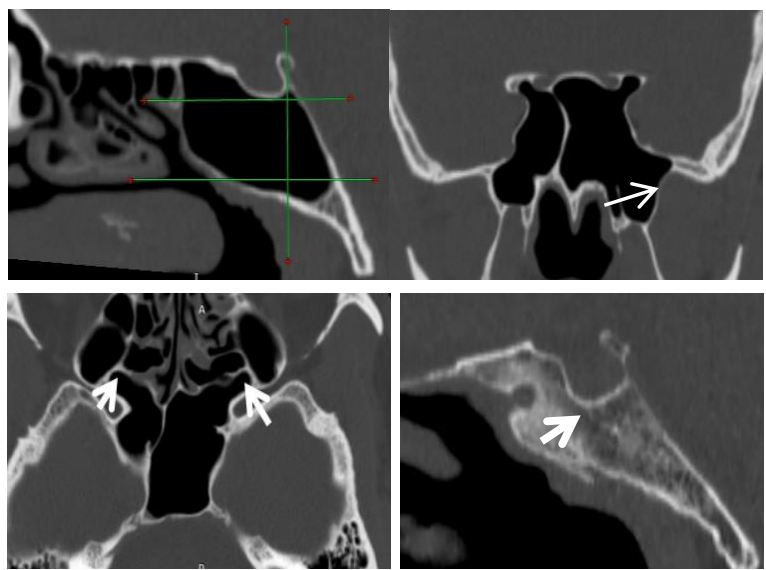

Hinh 3.1. Hình $C T$ theo 3 măt phằng (MP) của xoang bướm, QS các dạng khí hóa XB Hình $A$ : QS trên MP đứng dọc XB khí hóa dạng dốc nền; Hình $B: Q S$ trên MP đứng ngang XB khí hóa dạng ngách bên (mũi tên đứt) và khí hóa dạng cánh nhỏ (mũi tên liên) ở cả 2 bên xoang). Hình C:Khí hóa kiểu lõm trước 2 bên .Hình D:QS trên MP đứng dọc dạng XB khí hóa hẹp

2. Liên quan của xoang bướm với các cấu trúc cận bên

Bảng 3.2. Tý lệ lồi của các câu trúc vào lòng xoang bướm

\begin{tabular}{|c|c|c|c|}
\hline $\begin{array}{c}\text { Các liôi } \\
\text { cấu trúc }\end{array}$ & $\begin{array}{c}\text { Phải } \\
(\mathbf{n = 6 0 )} \\
\mathbf{n}(\mathbf{\%})\end{array}$ & $\begin{array}{c}\text { Trái } \\
(\mathbf{n = 6 0 )} \\
\mathbf{n}(\mathbf{\%})\end{array}$ & $\begin{array}{c}\text { Tống } \\
(\mathbf{n = 1 2 0 )} \\
\mathbf{n ( \% )}\end{array}$ \\
\hline ĐMCT & $42(70)$ & $44(72,4)$ & $86(71,2)$ \\
\hline TKTG & $29(48,3)$ & $30(50)$ & $59(49,2)$ \\
\hline TKV2 & $22(36,7)$ & $23(38,3)$ & $45(37,5)$ \\
\hline TK vidian & $24(40)$ & $29(48,3)$ & $53(44,2)$ \\
\hline
\end{tabular}

Nhận xét: Trong các cấu trúc cận 2 bên xoang bướm thì ĐMCT lồi vào lòng xoang bướm khá thường gặp với tỷ lệ $71,2 \%$, lồi ống thần kinh thị giác là $49,2 \%$, ít hơn là lồi ống thần kinh Vidian với $44,2 \%$ và ống TKV2 là $37,5 \%$.
Bảng 3.3. Tỷ lệ phơi trần vào lòng xoang bướm của các câu trúc cân bên

\begin{tabular}{|c|c|c|c|}
\hline $\begin{array}{c}\text { Phơi trấn } \\
\text { của các } \\
\text { cấu trúc }\end{array}$ & $\begin{array}{c}\text { Phải } \\
(\mathbf{n = 6 0 )} \\
\mathbf{n}(\mathbf{\%})\end{array}$ & $\begin{array}{c}\text { Trái } \\
(\mathbf{n = 6 0 )} \\
\mathbf{n ( \% )}\end{array}$ & $\begin{array}{c}\text { Tống } \\
(\mathbf{n = 1 2 0} \\
\mathbf{n}(\mathbf{\%})\end{array}$ \\
\hline ĐMCT & $5(8,3)$ & $7(11,7)$ & $12(10)$ \\
\hline TKTG & $6(10)$ & $3(5)$ & $9(7,5)$ \\
\hline TKV2 & $2(3,3)$ & $2(3,3)$ & $4(3,3)$ \\
\hline TK vidian & $11(18,3)$ & $12(20)$ & $23(19,2)$ \\
\hline
\end{tabular}

Nhân xét: Trong các cấu trúc cận 2 bên xoang bướm, TK vidian phơi trần trong lòng xoang bướm có tỷ lệ cao nhất $19,2 \%$, tiếp đến là ĐMCT với $10 \%$, ít hơn nữa là TKTG với $7,5 \%$ và ít phơi trần nhất là TKV2 với tỷ lệ 3,3\%

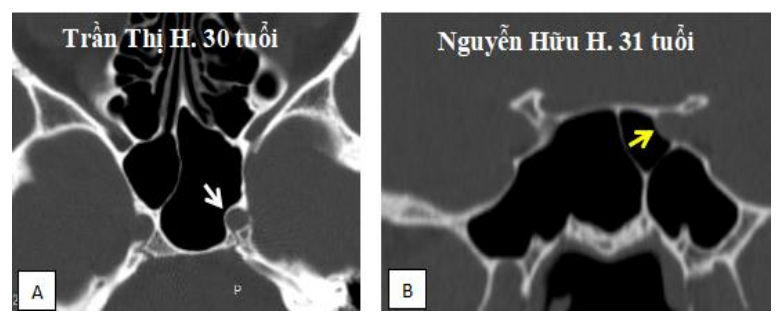

Hình 3.2. Hình ảnh CLVT biểu hiện liên quan các cấu trúc cận bên trên

A. Lồi ĐMCT;

B. Phơi trần ĐMCT (mũi tên vàng liền), lồi và phơi trần TKVidian (mũi tên trắng đứt)

C. Lồi TKTG (mũi tên trắng liền), lồi TKV2 (mũi tên vàng đứt)

D. Phơi trân TKTG (mũi tên vàng liền), phơi trần TKV2 (mũi tên trắng đứt)

Bảng 3.4. Liên quan giữa xoang bướm khí hóa MR ngách bên với lồi ĐMCT, TKV2, TKVidian

\begin{tabular}{|c|c|c|c|}
\hline \multirow{2}{*}{$\begin{array}{c}\text { Các lồi } \\
\text { cấu trúc }\end{array}$} & \multicolumn{2}{|c|}{$\begin{array}{c}\text { Khí hóa dáng } \\
\text { ngách bến }\end{array}$} & \multirow{2}{*}{ p value } \\
\cline { 2 - 3 } & $\begin{array}{c}\text { Có } \\
\mathrm{n}(\%)\end{array}$ & $\begin{array}{c}\text { Không } \\
\mathrm{n}(\%)\end{array}$ & \\
\hline ĐMCT & $55(64)$ & $31(46)$ & $\mathrm{P}<0,001$ \\
\hline
\end{tabular}


\begin{tabular}{|l|c|c|c|} 
TKV2 & $41(91,1)$ & $4(8,9)$ & $\mathrm{P}<0,001$ \\
\hline
\end{tabular}

\begin{tabular}{|c|c|c|c|}
\hline TK vidian & $50(94,3)$ & $3(5,7)$ & $\mathrm{P}<0,001$ \\
\hline
\end{tabular}

Nhận xét: Khi tỷ lệ khí hóa ngách bên tăng thì ĐMCT, TKV2, TKVidian nhô vào lòng xoang bướm tăng với $p<0,0001$

Bảng 3.5. Liên quan giữa xoang bướm khi hóa MR cánh nhỏ với lồi ông TKTG

\begin{tabular}{|c|c|c|c|}
\hline \multirow{2}{*}{$\begin{array}{c}\text { Lôi } \\
\text { TKTG }\end{array}$} & \multicolumn{2}{|c|}{ Khí hóa dạng cánh nhó } & \multirow{2}{*}{ p value } \\
\cline { 2 - 3 } & Cón & Không n (\%) & \\
\hline Không & $1(1,6)$ & $60(98,4)$ & \multirow{2}{*}{$\mathrm{P}<0,001$} \\
\hline Có & $34(57,6)$ & $25(42,4)$ & \\
\hline
\end{tabular}

Nhânn xét; Khi không có sự khí hóa cánh nhỏ và mấu yên trước TKTG lồi vào lòng xoang bướm rất ít, sự khí hóa cánh nhỏ và mấu yên trước tăng TKTG lồi vào lòng xoang bướm tăng với $p$ $<0,001$

\section{BÀN LUÂN}

1. Hình thái xoang bướm theo sự khí hóa xoang bướm. Xoang bướm là xoang cạnh mũi nằm ở trung tâm nền sọ. Hình thái của xoang bướm khá biển đổi phụ thuộc theo sự khí hóa của xoang. Xoang có thể mở rộng theo các phía ra trước, ra sau, sang hai bên lên trên và xuống dưới ngoại thân xương bướm. Sự khí hóa mở rộng khác nhau dẫn đến những biến đổi liên quan của các câu trúc cận bên như ĐMCT, TKTG, TKV2 và TK Vidian. Xoang bướm và các cấu trúc cận bên có thể ngăn cách nhau bằng vách xương khá mỏng hoặc không còn vách xương này[1].

Trong nghiên cứu của chúng tôi, hình thái khí hóa mở rộng xoang bướm dạng dốc nền và ngách bên chiếm đa số với tỷ lệ đều là 63\%, dạng cánh nhỏ là 30\% và dạng lốm trước ít gặp nhất với tỷ lệ là 20\%. Các dạng hình thái khí hóa MR này theo nghiên cứu của J Wang [3] là: 68\% loại dốc nền, $46 \%$ dạng ngách bên, 32\% dạng cánh nhỏ và $12 \%$ là tỷ lệ kiểu lõm trước. Nghiên cứu của Hiremath [4] trên người dân Ấn Độ với tỷ lệ các dạng khí hóa mở rộng: dốc nền, ngách bên, cánh nhỏ và kiểu lõm trước có tỷ lệ lần lượt là: $76,6 \%, 59,7 \%, 20,4 \%$ và 20,4\%.Như vậy kết quả nghiên cứu của chúng tôi và các tác giả thì dạng khí hóa mở rộng phổ biến là dốc nền và ngách bên, điều này một lần nữa cũng cố thêm số liệu về tỷ lệ dạng mở rộng của xoang bướm, đó có thể là gợi ý chọn đường tiếp cận đến tônn thương vùng dốc nền, hố sọ giữa cho bác sĩ trong phẫu thuật nội soi qua xoang bướm.

Khí hóa dốc nền tạo cơ sở cho con đường tiếp cận đến vùng dốc nền bắt đâu từ lỗ lớn xương chẩm đến lưng yên, liên quan ở vùng này có nguyên ủy các dây thân kinh từ thân não thoát ra, bể não thất, những trường hợp u dây thân kinh sọ não đoạn này thì khí hóa vào dốc nền là một gợi ý đường mổ thuận lợi cho bác sĩ phẫu thuất.

Khí hóa ngách bên tạo các ngách vào chân bướm, cánh lớn hay cả hai. Những ngách này bên dưới sàn sọ giữa tiếp cận mặt trước trong hay trước ngoài của hố sọ giữa tạo tiện lợi tiếp cận vùng trước trong xoang hang, hố sọ giữa mà ngày nay phẫu thuật sàn sọ đặc biệt chuyên ngành phẫu thuật thẩn kinh đang phát triển.

Khí hóa dạng cánh nhỏ mức độ khí hóa có thể rất ít (không hoàn toàn) chỉ tạo thành một ngách giữa lồi ống thân kinh thị giác và lồi động mạch cảnh trong gọi là ngách cảnh thị [2], hay khí hóa mở rộng hoàn toàn vào mấu giường trước dấn đến thân kinh thị giác và động mạch cảnh trong lồi hoặc chạy trong xoang bướm. Khí hóa mở rộng cánh nhỏ có thể cung cấp một hành lang phẫu thuật vùng trước ngoài hố yên (vùng câu vai xương bướm) nhưng cũng cân lưu ý vì thân kinh thị giác và động mạch cảnh trong vùng này có thể bị tổn thương khi phẫu thuật.

Khí hóa mở rộng dạng lõm trước: Một phân Iõm ở thành trước bắt nguôn từ phân bên của mào bướm mở rộng ra trước vượt qua mào bướm (đỉnh bướm) trên mặt phẳng nằm ngang. Trong kết quả nghiên cứu của chúng tôi các xoang có phân lõm trước gặp 12/60 trường hợp 20\%. Đây là dạng ít gặp nhất [3],[4]. Khi phân Iõm trước mở rộng theo hướng đi đến phía trên ống chân bướm khẩu cái và về phía xoang hàm sẽ đẩy xoang sàng ra trước và phân lõm trước được ngăn cách với xoang hàm bởi một vách xướng mỏng gọi là tấm hàm bướm[3]. Điều này cho phép một đường đi vào xoang bướm qua xoang hàm. Tuy nhiên trong dạng khí hóa mở rộng lõm trước, thành trên của ống bướm khẩu cái nằm ngay dưới sàn của phân lõm trước. Vì vậy khi chọn đường tiếp cận đến tổn thương từ xoang hàm vào xoang bướm cân lưu ý bó mạch thân kinh chân bướm khẩu cái nằm ngày dưới sàn phân lõm này.

2. Liên quan giữa xoang bướm với các thành phân cận bên. Theo kết quả thu được tỷ lệ phân lồi ra của ĐMCT được tìm thấy trong $71,2 \%$ phơi trân là $10 \%$, lôi TKTG là 49,2\%, phơi trân là 7,5\%. Ngoài ra phân lồi và phơi trân của TKV2 và TK Vidian được quan sát thấy ở $37,5 \%$ và $3,3 \% ; 44,2 \%$ và $19,2 \%$. Theo báo cáo của Hewaidi và Omami[1] tỷ lệ lồi ĐMCT, TKTG, TKV2 và TK Vidian lân lượt là 41\%, $35,6 \%, 24,3 \%$ và $27 \%$ sự phơi trân lần lượt là: 
$30 \%, 30,6 \%, 13 \%$ và $37 \%$. Theo Rahmati $A$ và cộng sự [5] lồi ĐMCT, TKTG, TKV2 và TKVidian là: $38,8 \%, 33 \%, 23,3 \%$ và $37,9 \%$.và Budu cùng cộng sự báo cáo tỷ lệ lồi ĐMCT là 34 - 99\% [6]. Có sự chênh lệch tỷ lệ này có thể do phương tiện kĩ thuật khác biệt và đối tượng nghiên cứu khác nhau. Các nghiên cứu đã đề cập đến mối tương quan có ý nghĩa thống kê giữa khí hóa dạng ngách bên với phần lồi của ĐMCT, TKV2 và TKVidian, điều đó cũng phù hợp với nghiên cứu của chúng tôi $(p<0,001)$. Cũng như mối tương quan của khí hóa dạng cánh nhỏ và mỏm yên trước có ý nghĩa thống kê của các tác giả trên và chúng tôi. Do đó như một quy luật khi quá trình khí hóa mở rộng càng tăng thì sự lồi của các cấu trúc mach thần kinh kế cận vào xoang bướm càng tăng. Lồi thần kinh thị tăng và có thể mất thành xương ngăn cách hoặc thành xương rất mỏng trong khí hóa mở rộng vào cánh nhỏ và mấu giường trước, hay thần kinh hàm trên (V2) và thần kinh Vidian và động mạch cảnh đoạn dưới yên trong khí hóa mở rộng bên. Điều này dẫn đến cấu trúc này tăng nhạy cảm và dễ bị tổn thương trong quá trình phẫu thuật nội soi.

Động mạch cảnh trong có sự liền quan mật thiết đến xoang bướm, ĐM đi ngay thành bền của xoang bướm trên một đoạn dài từ sau ra trước bắt đầu khi động mạch cảnh trong vào so đi trong ống cảnh rồi thoát vào trong sọ qua lố động mach cảnh đi vào xoang hang ở hai bên thân xương bướm, trong xoang hang ĐM chạy ra trước, sau đó chay lên trên vào trong mỏm yên trước.Đường đi của động mạch sẽ tạo nên một rãnh trên xương gọi là rãnh cảnh. Khi xoang bướm khí hóa mạnh từ bên trong làm thành xương bị bào mòn và rãnh cảnh sẽ tạo nên lồi của ĐM cảnh vào trong xoang bướm gấy ra nguy cơ tổn thương động mạch trong phẫu thuật xoang bướm và nội soi qua xoang bướm. Nguy cơ tử vong có thể xảy ra vì chúng ta gần như không thể cầm máu động mach cảnh trong ở vị trí này Vậy nên trước khi phẫu thuật phẫu thuật viên phải biết được khả năng có sự biến đổi này trên thành xoang bướm để tránh những biến chứng nguy hiểm trước khi vào phẫu thuật [2].

Những phần lồi dây thần kinh thị giác có thể tổn thương gây mù trong quá trình phẫu thuật hoặc là một biến chứng của viêm xoang gây nển sưy giảm thị lực, thiếu máu cục bộ và tắc nghẽn dẫn truyền thần kinh. Tỷ lệ î̀i ra của dây thần kinh thị giác tăng khi sự khí hóa dạng cánh nhỏ tăng[1], [5].
Trong phẫu thuật nội soi qua xoang bướm, lồi hoặc phơi trần của thần kinh V2 như là một yếu tố nguy cơ làm tăng sự tổn thương, hơn nữa TKV2 có thể bị tổn thương trong viêm xoang bướm vơi biểu hiện của một đau dây thần kinh V2.

Việc xác định vị trí cững như liên quan của thần kinh Vidian cho phẫu thuật thần kinh Vidian và những phẫu thuật nền sọ thông qua nội soi qua xoang bướm nhằm đến những khối u xung quang thần kinh Vidian là vô cùng cần thiết trước khi phẫu thuật. Sự liên quan của ống thần kinh Vidian với sự khí hóa mở rộng ngách bên của xoang bướm có ý nghĩa quan trọng cho việc chon cách tiếp cận thích hợp trong phẫu thuật nhằm làm giảm tối đa các biến chứng đến thần kinh này

\section{KẾT LUẬN}

Qua khảo sát và nghiên cứu hình ảnh phim chụp cắt lớp vi tính đa dãy, chúng tôi đã cung cấp nhưng thông tin về hình thái khí hóa và liên quan với các cấu trúc cận bên của xoang bướm. Đây là một trong những bước khảo sát trước mổ quan trọng trong phẫu thuật nội soi mũi xoang qua xoang bướm nhằm tìm ra con đường tiếp cận tốt đến tổn thương vùng yên hay mở rộng vùng quanh yên, từ đó hạn chế tối đa nhứng biến chứng trong và sau phẫu thuật. Ngoài ra sự liên quan có ý nghĩa $(p<0,001)$ giữa hình thái xoang bướm và các cấu trúc thần kinh mạch máu cận bên giúp nhận định nguyên nhân và hướng điều trị trong những trường hợp dò dịch não tủy qua mũi và bệnh lý viêm nhiễm mũi xoang.

\section{TÀI LIỆU THAM KHẢO}

1. Hewaidi G H and Omami G M. (2008) Anatomic variation of sphenoid sinus and related structures in Libyan population: CT Scan Study. Libyan J Med. AOP. 128-133

2. Rhoton. A (2012). Surgical anatomy of the sellar region, Transphenoidal surgery, Elservier Sanders, Philadelphia, 92 - 119.

3. Jian Wang, Sharatchandra $\mathbf{S}$ Bidari, Kohei Inoue, et al. (2010). Extensions of the sphenoid sinus: a new classification. Neurosurgery. 66, 797-816.

4. Hiremath, et al.(2018). Variations in sphenoid sinus pneumatization in Indian population. Indian Journal of Radiology and Imaging.28, $273-279$.

5. Rahmati A et al.(2016). Normal Variations of Sphenoid Sinus and the Adjacent Structures Detected inCone Beam Computed Tomography. J Dent Shiraz Univ Med Sci. 17(1): 32-37.

6. Budu $\mathbf{v}$ et al. (2013). The anatomical relations of the sphenoid sinus and their implications in sphenoid endoscopic surgery. Rom J Morphol Embryol. 54, 13- 16. 